\title{
Effects of conjugated linoleic acid on linoleic and linolenic acid metabolism in man
}

\author{
Anu M. Turpeinen ${ }^{1}$, Sonja Bärlund ${ }^{1}$, Riitta Freese ${ }^{1}$, Peter Lawrence ${ }^{2}$ and J. Thomas Brenna ${ }^{2}$ \\ ${ }^{1}$ Department of Applied Chemistry and Microbiology (Nutrition), University of Helsinki, PO Box 66, 00014 University of Helsinki, \\ Finland \\ ${ }^{2}$ Division of Nutritional Sciences, Cornell University, Ithaca, NY, USA
}

(Received 16 September 2004 - Revised 11 January 2005 - Accepted 13 January 2005)

Evidence from animal studies suggests that conjugated linoleic acid (CLA) modulates plasma and tissue appearance of newly synthesized PUFA. The effects of a $1.2 \mathrm{~g}(0.5 \%$ energy) daily intake of the cis-9,trans-11 (c9,t11) isomer of CLA, trans-10,cis-12 (t10,c12) isomer of CLA or olive oil (placebo) on linoleic acid (LA) and linolenic acid (LNA) metabolism in healthy human volunteers was investigated. Fifteen subjects were fed an experimental diet and supplemented with $c 9, t 11$-CLA, $t 10, c 12$-CLA or placebo for $7 \mathrm{~d}$ before consuming a tracer dose of U-[ $\left.{ }^{13} \mathrm{C}\right] \mathrm{LA}(50 \mathrm{mg})$ and U- $\left[{ }^{13} \mathrm{C}\right]$ LNA $(50 \mathrm{mg})$. Blood samples were taken at $0,2,4,6,8,24,48,72$ and $168 \mathrm{~h}$ and analysed using high-precision MS. No differences between the groups in peak plasma $\left[{ }^{13} \mathrm{C}\right] \mathrm{LA}(10 \cdot 3-11 \cdot 6 \%$ of dose $),\left[{ }^{13} \mathrm{C}\right] \mathrm{LNA}(2 \cdot 5-2 \cdot 9 \%$ of dose $)$, $\left[{ }^{13} \mathrm{C}\right]$ arachidonic acid $(0 \cdot 09-0 \cdot 12 \%$ of dose), $\left[{ }^{13} \mathrm{C}\right]$ EPA $\left(0.04-0.06 \%\right.$ of dose) or $\left[{ }^{13} \mathrm{C}\right]$ DHA $(0 \cdot 06-0.10 \%$ of dose) were detected. Concentration $v$. time curves (area under the curve) also showed no significant differences between groups. This suggests that, in healthy human subjects consuming a diet with adequate intake of essential fatty acids, CLA does not affect metabolism of LA or LNA.

Conjugated linoleic acid: Linoleic acid: Linolenic acid: Stable isotope: Man

A multitude of physiological effects for conjugated positional and geometrical isomers of linoleic acid (conjugated linoleic acid; CLA), specifically the cis-9,trans-11 $(c 9, t 11)$ and trans-10,cis-12 $(t 10, c 12)$ isomers, have been observed (Pariza et al. 2001), but the mechanisms involved are still unresolved. Altered eicosanoid synthesis, involving changes in the metabolism of essential fatty acids, has been proposed as a mechanism by which CLA may exert some of its effects (Banni et al. 1999a,b; Belury, 2002). Considering the multitude of functions for essential fatty acids in the body, this may result in widespread physiological effects.

CLA feeding is associated with altered tissue fatty acid composition, reflecting competition with other fatty acids for incorporation into tissues. Changes in saturated, monounsaturated and polyunsaturated fatty acids have been reported in animals (Belury \& Kempa-Steczko, 1997; Banni et al. 1999b; Badinga et al. 2003; Ostrowska et al. 2003). Evidence from animal and cell culture studies suggests that CLA inhibits several enzymes involved in fatty acid metabolism, namely $\Delta^{9}$-desaturase, $\Delta^{6}$ desaturase and elongases (Bretillon et al. 1999; Chuang et al. 2001a,b; Sebedio et al. 2001; Loor et al. 2003).

Significant changes have been seen especially in linoleic acid (LA) and its metabolites. Tissue concentrations of LA and arachidonic acid (AA) decreased by up to $50 \%$ in various animal species by feeding $0.5-1.5 \%$ CLA (Belury \&
Kempa-Steczko, 1997; Kramer et al. 1998; Banni et al. 1999b; Du et al. 2000; Ramsay et al. 2001). Effects have been most prominent in tissues containing neutral lipids, such as mammary and adipose tissue. Cell culture studies with pure isomers have shown that the $c 9, t 11$ isomer of CLA is a stronger inhibitor of $\Delta^{6}$-desaturase and LA desaturation than the $t 10, c 12$ isomer (Bretillon et al. 1999; Chuang et al. 2001a). Both $c 9, t 11-$ CLA and $t 10, c 12-$ CLA also inhibited elongation of LA by $20-60 \%$ (Chuang et al. $2001 b$ ). Desaturation and elongation of $\alpha$-linolenic acid (LNA) was affected only slightly by both isomers (Bretillon et al. 1999).

Data in man are scarce. In supplementation studies, only minor changes in plasma fatty acids have been observed (Benito et al. 2001a,b; Mougios et al. 2001; Noone et al. 2002; Petridou et al. 2003). The only tracer study thus far found no effects of consuming $3.9 \mathrm{~g}$ CLA mixture on incorporation of deuterated oleic acid or LA in plasma lipid fractions(Emken et al. 2002). However, the concentration of desaturation and elongation products was too low to allow accurate quantification and it remains to be resolved whether LA metabolism is affected by CLA in man.

Our aim was to study the effects of two main CLA isomers, $c 9, t 11$ and $t 10, c 12$, on the desaturation of LA and LNA in healthy human subjects using uniformly ${ }^{13} \mathrm{C}$-labelled LA and LNA.

Abbreviations: AA, arachidonic acid; AUC, area under the curve; $C$, cis; CE, cholesterol esters; CLA, conjugated linoleic acid; FAME, fatty acid methyl esters; GCC-IRMS, GC-combustion isotope ratio mass spectrometer; LA, linoleic acid; LNA, linolenic acid; PC, phosphatidylcholine; PE, phosphatidyl ethanolamine; $t$, trans; TAG, triacylglycerols.

* Corresponding author: Dr Anu Turpeinen, fax +358 9 19158269, email anu.turpeinen@helsinki.fi 


\section{Materials and methods}

\section{Subjects}

Fifteen healthy subjects participated in the study. Only healthy adults ( $>17$ years), both male and female, were accepted. Pregnant or lactating women were excluded, as were subjects with any metabolic conditions. Subjects underwent health screening, consisting of a general health questionnaire and measurement of weight, height and blood pressure. A blood sample was analysed for lipid parameters and a urine sample for protein and glucose. Baseline characteristics of the subjects are presented in Table 1.

\section{Ethical considerations}

The proposal was reviewed by the Ethical Committee of the University of Helsinki and by the Cornell University Committee on Human Subjects. The subjects gave their informed consent before entering the study.

\section{Experimental supplements and diet}

Subjects were randomly allocated into three groups (four women and one man in each group) to receive $c 9, t 11$ isomer of CLA, $t 10, c 12$ isomer of CLA or olive oil as placebo (Natural Inc., Hovdebygda, Norway). Two gelatine-coated capsules, each containing $750 \mathrm{mg}$ fatty acids, were consumed daily with lunch. The $c 9, t 11$-CLA capsules contained $79 \%$ of the $c 9, t 11$ isomer, $7.8 \%$ of the $t 10, c 12$ isomer, $5.8 \%$ of oleic acid (18:1), $0.3 \%$ of the $c 9, c 11$ and $c 10, c 12$ isomers, and $2.1 \%$ of the $t 9, t 11$ and $t 10, t 12$ isomers. The $t 10, c 12$-CLA capsules contained $84 \%$ of the $t 10, c 12$ isomer, $10.6 \%$ of the $c 9, t 11$ isomer, $1.6 \%$ of $c 9-18: 1,0.8 \%$ of the $c 9, c 11$ and $c 10, c 12$ isomers, and $2.3 \%$ of the $t 9, t 11$ and $t 10, t 12$ isomers. The capsules thus provided $1.19 \mathrm{~g} c 9, t 11-\mathrm{CLA} / \mathrm{d}$ and $1.26 \mathrm{~g} t 10, c 12-$ CLA/d. Olive oil capsules contained $73.5 \% 18: 1$ and $<1 \%$ CLA. Compliance assessed by capsule counting was $99 \%$. The subjects and personnel who analysed plasma samples were blinded to the treatment.

The total length of the study was $14 \mathrm{~d}$. Subjects were freeliving, but their fat intake was controlled. On weekdays, the subjects came to have a standardized lunch at the University premises. On Fridays, ready-to-eat meals were provided for Saturday and Sunday. The subjects were also supplied with olive oil, margarine, bread and bakery products containing olive oil and instructed on how much to consume each day. They were also given a list of foods and food items prohibited during the study (fish and foods containing CLA, e.g. fatty milk products, beef, lamb and turkey). All subjects kept a $3 \mathrm{~d}$ food record, consisting of two weekdays and one day during the weekend. Energy and nutrient intakes were calculated using the Flamingo nutrition calculation program (version 1.3.2, 2000; Dipper Software, Helsinki, Finland). The calculated composition of the diets is shown in Table 2 .

\section{Dosing}

After $6 \mathrm{~d}$ on the experimental diet, on the morning of day 7 , the subjects gave a fasting blood sample before ingesting approximately $50 \mathrm{mg} \mathrm{U}-\left[{ }^{13} \mathrm{C}\right] \mathrm{LA}(46 \cdot 0-51.4 \mathrm{mg})$ and $50 \mathrm{mg}$ $\mathrm{U}-\left[{ }^{13} \mathrm{C}\right]$ LNA $(48.4-52.6 \mathrm{mg})$ with a standard breakfast. The tracer dose was weighed individually for each subject and injected into a sugar cube. The breakfast consisted of a muffin (containing $10 \mathrm{~g}$ olive oil), orange juice, fat-free yoghurt and coffee or tea. Uniformly ${ }^{13} \mathrm{C}$-labelled LA (free fatty acid, $98 \%$ purity) was purchased from Spectra Stable Isotopes (Columbia, MD, USA). Uniformly ${ }^{13} \mathrm{C}$-labelled LNA (ethyl ester, $98 \%$ purity) was purchased from Cambridge Isotope Labs (Andover, MA, USA).

\section{Sampling}

Blood samples were taken at 2, 4, 6 and $8 \mathrm{~h}$ after the dose. After the $4 \mathrm{~h}$ blood sample, the subjects had lunch and after the $6 \mathrm{~h}$ sample they were provided with an orange as a snack. Thereafter the subjects continued on the diet and overnight fasting blood samples were taken on three consecutive mornings. The last sample was taken 1 week (168 h) after the dosing.

Blood was taken into Vacutainer ${ }^{\mathrm{TM}}$ EDTA tubes and kept on ice before separating plasma by centrifugation. Plasma was snap-frozen and stored at $-70^{\circ} \mathrm{C}$.

\section{Analyses}

Plasma total fatty acids were analysed from all samples. Total lipids were extracted using a modified Bligh and Dyer method

Table 1. Baseline characteristics of subjects

(Mean values with their standard deviations)

\begin{tabular}{|c|c|c|c|c|c|c|c|}
\hline & \multicolumn{6}{|c|}{ Study group } & \multirow[b]{3}{*}{$P^{*}$} \\
\hline & \multicolumn{2}{|c|}{$c 9, t 11-C L A$} & \multicolumn{2}{|c|}{$t 10, c 12-C L A$} & \multicolumn{2}{|c|}{ Control } & \\
\hline & Mean & SD & Mean & SD & Mean & SD & \\
\hline Age (years) & $36 \cdot 4$ & $14 \cdot 4$ & $26 \cdot 0$ & $6 \cdot 9$ & $32 \cdot 0$ & $14 \cdot 8$ & 0.44 \\
\hline BMI $\left(\mathrm{kg} / \mathrm{m}^{2}\right)$ & $23 \cdot 4$ & $4 \cdot 2$ & $23 \cdot 0$ & $2 \cdot 5$ & $22 \cdot 7$ & $2 \cdot 3$ & 0.93 \\
\hline Systolic blood pressure (mmHg) & 123 & 19 & 122 & 14 & 114 & 10 & 0.56 \\
\hline Diastolic blood pressure $(\mathrm{mmHg})$ & 78 & 12 & 79 & 9 & 73 & 10 & 0.63 \\
\hline Serum cholesterol $(\mathrm{mmol} / \mathrm{l})$ & 4.8 & 0.6 & $5 \cdot 0$ & 0.9 & $4 \cdot 3$ & 0.3 & 0.92 \\
\hline Serum triacylglycerols (mmol/l) & 1.6 & $1 \cdot 3$ & $1 \cdot 8$ & $1 \cdot 1$ & 0.9 & 0.1 & 0.64 \\
\hline Serum HDL-cholesterol (mmol/l) & $2 \cdot 2$ & 0.5 & $2 \cdot 0$ & 0.3 & $2 \cdot 1$ & 0.5 & 0.70 \\
\hline Serum LDL-cholesterol (mmol/l) & $2 \cdot 9$ & 0.5 & $3 \cdot 1$ & 0.9 & 2.9 & 1.0 & 0.89 \\
\hline
\end{tabular}

c9,t11-CLA, cis-9,trans-11 conjugated linoleic acid; t10,c12-CLA, trans-10,cis-12 conjugated linoleic acid.

${ }^{*}$ Difference between groups (one-way ANOVA).

For details of subjects and procedures, see this page. 
Table 2. Calculated composition of diets based on food records

(Mean values with their standard deviations)

\begin{tabular}{|c|c|c|c|c|c|c|c|}
\hline & \multicolumn{6}{|c|}{ Study group } & \multirow[b]{3}{*}{$P^{*}$} \\
\hline & \multicolumn{2}{|c|}{$c 9, t 11-C L A$} & \multicolumn{2}{|c|}{$t 10, c 12-C L A$} & \multicolumn{2}{|c|}{ Control } & \\
\hline & Mean & SD & Mean & SD & Mean & SD & \\
\hline Energy (MJ) & $9 \cdot 8$ & $2 \cdot 6$ & $9 \cdot 0$ & $1 \cdot 1$ & $9 \cdot 3$ & $2 \cdot 2$ & 0.85 \\
\hline Protein (\% energy) & $11 \cdot 3$ & $2 \cdot 3$ & $13 \cdot 4$ & $1 \cdot 7$ & $10 \cdot 7$ & $2 \cdot 6$ & 0.18 \\
\hline Carbohydrates (\% energy) & $47 \cdot 5$ & $7 \cdot 6$ & $45 \cdot 4$ & $3 \cdot 2$ & $50 \cdot 1$ & $7 \cdot 2$ & 0.52 \\
\hline Fat (\% energy) & $37 \cdot 5$ & $5 \cdot 9$ & $37 \cdot 4$ & $4 \cdot 6$ & $35 \cdot 3$ & 4.5 & 0.75 \\
\hline SFA ( $\%$ energy) & $6 \cdot 7$ & $1 \cdot 3$ & $7 \cdot 2$ & $2 \cdot 3$ & $6 \cdot 1$ & 1.7 & 0.60 \\
\hline MUFA (\% energy) & $19 \cdot 7$ & 3.9 & $18 \cdot 4$ & $3 \cdot 4$ & $18 \cdot 0$ & $2 \cdot 0$ & 0.76 \\
\hline PUFA (\% energy) & $5 \cdot 9$ & $1 \cdot 0$ & 4.9 & 0.8 & $4 \cdot 8$ & 1.0 & 0.17 \\
\hline LA (\% energy) & $5 \cdot 1$ & 0.8 & $4 \cdot 2$ & $6 \cdot 3$ & $4 \cdot 3$ & $1 \cdot 1$ & 0.32 \\
\hline LNA (\% energy) & 0.9 & 0.1 & 0.7 & 0.3 & 0.6 & 0.3 & 0.21 \\
\hline Cholesterol (mg) & 110 & 65 & 106 & 16 & 97 & 40 & 0.90 \\
\hline
\end{tabular}

c9,t11-CLA, cis-9,trans-11 conjugated linoleic acid; t10,c12-CLA, trans-10,cis-12 conjugated linoleic acid; SFA,

saturated fatty acids; LA, linoleic acid; LNA, linolenic acid.

* Difference between groups (one-way ANOVA).

For details of diets and procedures, see p. 728.

(Bligh \& Dyer, 1959; Scheaff et al. 1995) and derivatized to fatty acid methyl esters (FAME) with $\mathrm{BF}_{3}$ in methanol. FAME were dissolved in heptane with butylated hydroxytoluene added to prevent oxidation. Freshly prepared triheptadecanoin (Matreya Inc., Pleasant Gap, PA, USA) was added as internal standard to each sample. The total fatty acids composition was determined by GC (HP 5890 GC with flame ionization detector; Hewlett Packard, Palo Alto, CA, USA), using a CPSil 88 for FAME capillary column $(100 \mathrm{~m} \times 0.25 \mathrm{~mm}$ internal diameter, $0.2 \mu \mathrm{m}$ film thickness; Chrompak, Middelburg, The Netherlands). $\mathrm{H}_{2}$ was used as carrier gas with a flow rate of $1.7 \mathrm{ml} / \mathrm{min}$. The temperature program used was from $80^{\circ} \mathrm{C}$ to $170^{\circ} \mathrm{C}$ at $10^{\circ} \mathrm{C} / \mathrm{min}$, then to $195^{\circ} \mathrm{C}$ at $1^{\circ} \mathrm{C} / \mathrm{min}$ and finally to $225^{\circ} \mathrm{C}$ at $10^{\circ} \mathrm{C} / \mathrm{min}$, where it was held for $30 \mathrm{~min}$. Total run time was $67 \mathrm{~min}$. Response factors for each fatty acid were obtained by an equal weight FAME mixture and calibrated with methyl heptadecanoate (Matreya Inc.) as an internal standard.

Main plasma lipid fractions were separated by TLC from $8 \mathrm{~h}$ samples. Triacylglycerols (TAG) and cholesterol esters (CE) were separated on a Silica G plate (Analtech, Newark, DE, USA) with hexane-diethyl ether $-88 \%$ formic acid (80:20:2, by vol.). Phosphatidyl ethanolamine (PE) and phosphatidylcholine (PC) were separated on a Silica H plate (Analtech) using a solvent mixture of chloroform-methanol-acetic acid-water (50:25:7:3, by vol.). TAG, CE, PC and PE standards (Matreya Inc. and Sigma, St. Louis, MO, USA) were used to identify the respective bands.

Tracer analyses for ${ }^{13} \mathrm{C}$ were performed using a high-precision GC-combustion isotope ratio mass spectrometer (GCC-IRMS; Finnigan MAT 252, Bremen, Germany) described in detail previously (Goodman \& Brenna, 1992).

\section{Calculations}

The concentration of tracer in tissues was calculated from the concentration of each fatty acid detected by GC and the atom percent excess (APE) of each fatty acid determined by the GCC-IRMS. Briefly, high-precision data are presented as the relative deviation from the international standard Pee Dee
Belemnite (PDB), with a ${ }^{13} \mathrm{C}:{ }^{12} \mathrm{C}$ isotope ratio $\left(R_{\mathrm{PDB}}\right)$ of 0.0112372, as:

$$
\delta^{13} \mathrm{C}_{\mathrm{PDB}}=\frac{R_{\mathrm{f}}-R_{\mathrm{PDB}}}{R_{\mathrm{PDB}}} \times 1000,
$$

where $R_{\mathrm{f}}$ is the ratio of the heavy to light isotope for the sample. Extracting $R_{\mathrm{f}}$ from equation (1), atom percent (AP) can be calculated, which is the percentage of the heavier isotope in the analyte peak:

$$
\mathrm{AP}_{\mathrm{f}}=\frac{R_{\mathrm{f}}}{1+R_{\mathrm{f}}} \times 100 .
$$

APE is calculated by subtracting the baseline sample $(0 \mathrm{~h}$ sample) from $\mathrm{AP}_{\mathrm{f}}$. The total amount of tracer can be calculated by multiplying the APE by the tracee concentration $\left(Q_{\mathrm{f}}\right)$ in tissues. This value is termed the molar dose equivalent:

$$
D^{*}=\frac{\mathrm{APE}_{\mathrm{f}}}{100} \times Q_{\mathrm{f}}
$$

To eliminate artifactual differences resulting from different oral amounts, results are normalized by the amount of labelled fatty acid consumed by the subject $(d)$ :

$$
\% \text { Dose }=\frac{D^{*}}{d}
$$

The $\%$ dose shows how much of the labelled fatty acid was transformed into products in terms of molar equivalents of the dosed fatty acids, $\left[{ }^{13} \mathrm{C}\right] \mathrm{LA}$ into $\left[{ }^{13} \mathrm{C}\right] \mathrm{AA}$ and $\left[{ }^{13} \mathrm{C}\right] \mathrm{LNA}$ into $\left[{ }^{13} \mathrm{C}\right] \mathrm{EPA}$ and $\left[{ }^{13} \mathrm{C}\right] \mathrm{DHA}$.

Concentration of the labelled fatty acid was plotted $v$. time (h) for each fatty acid and the total area under the curve (AUC; ng/ $\mathrm{ml}$ plasma) was calculated according to Matthews et al. (1990) to obtain a relative measure of the amount of label appearing in a given fraction over the specified time period $(168 \mathrm{~h})$.

\section{Statistical analyses}

Results are expressed as mean and standard deviation. Differences between groups in baseline parameters, dietary data, fatty acids, AUC data and tracer data were analysed using 
one-way ANOVA with the Tukey HSD post hoc test (SPSS 10.0; SPSS Inc., Chicago, IL, USA). Significance was declared at $P<0 \cdot 05$.

\section{Results}

All subjects successfully completed the study. The controls were taller than subjects in the CLA groups, but there were no other differences in baseline characteristics (Table 1). There were also no differences in dietary intake, based on $3 \mathrm{~d}$ food records, between the three groups (Table 2). Percentage of energy intake from fat was on average 37 , from protein 12 and from carbohydrates 48 . LA intakes in the $c 9, t 11$-CLA, $t 10, c 12$-CLA and control groups were $5.1 \%, 4.2 \%$ and $4.3 \%$ energy, respectively, and LNA intakes $0.9 \%, 0.7 \%$ and $0.6 \%$ energy, respectively.

\section{Plasma total and lipid fraction fatty acids}

Plasma total fatty acids showed expected differences between the groups in the concentrations of $c 9, t 11$-CLA and $t 10, c 12-$ CLA (Table 3). DHA was higher in both CLA groups compared with controls $(P=0.02)$. Other major fatty acids did not reveal significant differences. Also, saturated:MUFA ratios, 16:0:16:1 and 18:0:18:1, did not differ between the groups.

There were significant differences in incorporation of the CLA isomers to specific plasma fractions. Highest concentrations of $c 9, t 11$-CLA were seen in TAG $(0.5 \mathrm{wt} \%)$, whereas $t 10, c 12-C L A$ was mainly incorporated into phospholipids, especially PC $(0 \cdot 2 \mathrm{wt} \%)$. $t 10, c 12$-CLA was not detected in all fractions in all samples.

Changes in other major fatty acids in plasma lipid fractions were few (Table 4). Concentrations of palmitic acid (16:0) in CE were higher in both the $c 9, t 11$-CLA and $t 10, c 12$-CLA groups than in controls $(P=0 \cdot 047)$. In TAG, 18:1 was lower

Table 3. Total plasma fatty acids (wt\%) of subjects fed cis-9,trans-11 conjugated linoleic acid (c9,t11-CLA), trans-10,cis-12 conjugated linoleic acid $(t 10, c 12-C L A)$ or placebo

(Mean values with their standard deviations)

\begin{tabular}{|c|c|c|c|c|c|c|c|}
\hline & \multicolumn{6}{|c|}{ Study group } & \multirow[b]{3}{*}{$P^{*}$} \\
\hline & \multicolumn{2}{|c|}{$c 9, t 11-\mathrm{CLA}$} & \multicolumn{2}{|c|}{$t 10, c 12-C L A$} & \multicolumn{2}{|c|}{ Control } & \\
\hline & Mean & SD & Mean & SD & Mean & $\mathrm{SD}$ & \\
\hline $14: 0$ & 1.0 & 0.7 & $1 \cdot 0$ & 0.3 & 1.0 & 0.4 & 0.98 \\
\hline $14: 1$ & 0.3 & 0.1 & $0 \cdot 2$ & 0.04 & 0.2 & $0 \cdot 1$ & 0.37 \\
\hline 16:0 & $29 \cdot 1$ & $1 \cdot 8$ & $29 \cdot 5$ & $3 \cdot 2$ & $29 \cdot 6$ & $4 \cdot 8$ & 0.97 \\
\hline $16: 1$ & $2 \cdot 4$ & 0.9 & $2 \cdot 1$ & 0.6 & $2 \cdot 7$ & $1 \cdot 2$ & 0.59 \\
\hline $16: 0: 16: 1$ & $13 \cdot 0$ & $2 \cdot 2$ & 14.5 & $3 \cdot 0$ & $12 \cdot 7$ & $1 \cdot 6$ & 0.67 \\
\hline 18:0:18:1 & 0.4 & 0.02 & 0.4 & 0.1 & 0.3 & $0 \cdot 1$ & 0.06 \\
\hline $18: 0$ & 9.9 & 0.4 & $10 \cdot 2$ & $1 \cdot 3$ & 8.9 & $1 \cdot 8$ & 0.30 \\
\hline $18: 1$ & $26 \cdot 3$ & 0.9 & $26 \cdot 6$ & 3.6 & $28 \cdot 9$ & $2 \cdot 6$ & 0.25 \\
\hline $18: 2 n-6$ & $26 \cdot 1$ & 3.9 & $24 \cdot 6$ & $2 \cdot 1$ & $23 \cdot 7$ & 3.6 & 0.52 \\
\hline$c 9, t 11-\mathrm{CLA}$ & 0.8 & 0.2 & 0.2 & 0.1 & 0.2 & $0 \cdot 1$ & $<0.001$ \\
\hline$t 10, c 12-C L A$ & 0.04 & 0.05 & 0.5 & 0.2 & $<0.01$ & & $<0.001$ \\
\hline $18: 3 n-3$ & 0.7 & 0.2 & $0 \cdot 7$ & 0.1 & 0.7 & 0.2 & 0.76 \\
\hline $20: 3 n-6$ & 0.2 & 0.1 & 0.2 & 0.1 & 0.6 & 0.8 & 0.34 \\
\hline $20: 4 n-6$ & $1 \cdot 1$ & 0.1 & $1 \cdot 3$ & 0.2 & 1.4 & 0.2 & 0.06 \\
\hline $20: 5 n-3$ & $0 \cdot 1$ & $0 \cdot 1$ & 0.2 & 0.1 & $0 \cdot 1$ & 0.1 & 0.36 \\
\hline $22: 6 n-3$ & $1 \cdot 0$ & 0.3 & 0.9 & 0.2 & 0.5 & 0.2 & 0.02 \\
\hline
\end{tabular}

* Difference between groups (one-way ANOVA).

For details of subjects and procedures, see p. 728. in the $c 9, t 11$-CLA group than in the $t 10, c 12$-CLA and control groups $(P=0 \cdot 037)$. However, no differences were seen in the ratios 16:0:16:1 and 18:0:18:1.

\section{Tracer analyses}

$\left[{ }^{13} \mathrm{C}\right]$ LA and $\left[{ }^{13} \mathrm{C}\right]$ LNA increased rapidly in plasma after tracer intake. $\left[{ }^{13} \mathrm{C}\right]$ LNA reached its peak concentration at $2 \mathrm{~h}$ and had almost returned to baseline at $72 \mathrm{~h}$. The peak for $\left[{ }^{13} \mathrm{C}\right]$ LA was at $8 \mathrm{~h}$ and its plasma concentration had almost returned to baseline at the end of the study $(168 \mathrm{~h})$. The mean amount of $\left[{ }^{13} \mathrm{C}\right] \mathrm{AA},\left[{ }^{13} \mathrm{C}\right] \mathrm{EPA}$ and $\left[{ }^{13} \mathrm{C}\right] \mathrm{DHA}$ in plasma increased slowly over time and peak concentrations were reached at $48-72 \mathrm{~h}, 24-48 \mathrm{~h}$ and $48 \mathrm{~h}$, respectively. Peak concentrations of AA were reached earlier in the $t 10, c 12$-CLA group than in the two other groups $(24 \mathrm{~h} v$. $48 \mathrm{~h}$ ), but differences in plasma concentrations were not significant. At $168 \mathrm{~h},\left[{ }^{13} \mathrm{C}\right] \mathrm{EPA}$ concentrations were near baseline whereas $\left[{ }^{13} \mathrm{C}\right] \mathrm{DHA}$ concentrations were still considerably above baseline for most subjects.

Peak plasma concentrations of $\left[{ }^{13} \mathrm{C}\right] \mathrm{LA}$ in the three groups were $4.7-5.6 \mathrm{ng} / \mathrm{ml}$, which corresponds to $10.3-11.6 \%$ of the oral dose. The corresponding values were $1.0-1 \cdot 3 \mathrm{ng} / \mathrm{ml}(2 \cdot 5-$ $2.9 \%$ of dose) for $\left[{ }^{13} \mathrm{C}\right] \mathrm{LNA}, 0.04-0.06 \mathrm{ng} / \mathrm{ml}(0.09-0.12 \%$ of LA dose) for $\left[{ }^{13} \mathrm{C}\right] \mathrm{AA}, 0.02-0.03 \mathrm{ng} / \mathrm{ml}(0.04-0.06 \%$ of LNA dose) for $\left[{ }^{13} \mathrm{C}\right] \mathrm{EPA}$ and $0.06-0.09 \mathrm{ng} / \mathrm{ml}(0.06-0.10 \%$ of LNA dose) for $\left[{ }^{13} \mathrm{C}\right] \mathrm{DHA}$. No significant differences between the groups in peak plasma concentrations or AUC data up to $168 \mathrm{~h}$ were detected for any of the fatty acids (Table 5).

\section{Discussion}

Evidence from animal and cell culture studies suggests that CLA affects tissue fatty acid composition, especially concentrations of LA and AA, by inhibiting $\Delta^{6}$-desaturase and elongase enzymes (Bretillon et al. 1999; Chuang et al. 2001a,b). We did not observe significant differences in desaturation or elongation of LA and LNA in healthy subjects consuming approximately $1.2 \mathrm{~g}(0.5 \%$ energy $) c 9, t 11$-CLA, $t 10, c 12-$ CLA or olive oil daily, either in concentrations of labelled metabolites or plasma kinetics of tracer fatty acids or metabolites. We have no reason to believe that this was due to too short a CLA supplementation period (6d) since in a previous study we showed that a steady state in plasma CLA is achieved in 4-6d (Turpeinen et al. 2002). Also, the CLA dose used should have been sufficient to elicit any effects even at high dietary intake levels. The average daily intake has been estimated to be on average a few hundred milligrams (Ritzenthaler et al. 2001; Fremann et al. 2002). Finnish women are reported to have a habitual CLA intake of $130 \mathrm{mg} / \mathrm{d}$ (Aro et al. 2000).

A recent stable isotope study investigated the accretion and metabolism of deuterated oleic acid $\left(c 9-18: 1-d_{8}\right)$, LA $\left(c 9, c 12-18: 2-d_{2}\right), c 9, t 11-C L A\left(c 9, t 11-18: 2-d_{6}\right)$ and $t 10, c 12-$ CLA $\left(t 10, c 12-18: 2-d_{4}\right)$ in six women who had consumed sunflower oil $6 \mathrm{~g} / \mathrm{d}$ or CLA (mixture of isomers) $3.9 \mathrm{~g} / \mathrm{d}$ for $63 \mathrm{~d}$ (Emken et al. 2002). In line with the present results, CLA isomers did not affect the incorporation of LA into plasma lipid fractions. However, only trace amounts of metabolites of LA were detected and thus the effects of CLA on desaturation and elongation of LA were not discussed. Since all other 
Table 4. Fatty acids (wt\%) in serum cholesterol esters (CE) and triacylglycerols (TAG) of subjects fed cis-9, trans-11 conjugated linoleic acid $(c 9, t 11-C L A)$, trans-10, cis-12 conjugated linoleic acid $(t 10, c 12-C L A)$ or olive oil placebo (control)

(Mean values with their standard deviations)

\begin{tabular}{|c|c|c|c|c|c|c|c|}
\hline & \multicolumn{6}{|c|}{ Study group } & \multirow[b]{3}{*}{$P^{*}$} \\
\hline & \multicolumn{2}{|c|}{$C 9, t 11-$ CLA } & \multicolumn{2}{|c|}{$t 10, c 12-C L A$} & \multicolumn{2}{|c|}{ Control } & \\
\hline & Mean & SD & Mean & SD & Mean & SD & \\
\hline \multicolumn{8}{|l|}{ CE } \\
\hline $16: 0$ & $23 \cdot 4$ & $2 \cdot 6$ & $21 \cdot 3$ & $2 \cdot 0$ & $17 \cdot 7$ & $2 \cdot 4$ & 0.05 \\
\hline $16: 1$ & $4 \cdot 1$ & 0.3 & 3.5 & 0.5 & $3 \cdot 3$ & 0.6 & 0.72 \\
\hline 16:0:16:1 & $5 \cdot 7$ & 0.6 & $6 \cdot 1$ & 1.0 & 4.9 & 0.8 & 0.09 \\
\hline $18: 0$ & $2 \cdot 0$ & 1.5 & 2.5 & 2.5 & 1.5 & 0.3 & 0.66 \\
\hline $18: 1$ & $28 \cdot 9$ & $2 \cdot 8$ & $28 \cdot 1$ & $2 \cdot 8$ & $28 \cdot 3$ & 1.8 & 0.41 \\
\hline 18:0:18:1 & 0.1 & 0.0 & 0.1 & 0.0 & 0.1 & 0.0 & 0.52 \\
\hline $18: 2 n-6$ & $34 \cdot 6$ & $2 \cdot 2$ & $37 \cdot 3$ & $2 \cdot 0$ & $35 \cdot 8$ & $2 \cdot 4$ & 0.28 \\
\hline $18: 3 n-3$ & 0.8 & 0.2 & 0.5 & 0.1 & 0.9 & 0.2 & $<0.01$ \\
\hline$c 9, t 11-C L A$ & 0.2 & 0.0 & 0.0 & 0.0 & 0.1 & 0.0 & $<0.01$ \\
\hline$t 10, c 12-C L A$ & 0.04 & 0.01 & 0.07 & 0.01 & 0.04 & 0.01 & 0.08 \\
\hline $20: 3 n-6$ & 0.5 & 0.5 & $1 \cdot 3$ & 0.7 & 0.5 & 0.5 & 0.06 \\
\hline $20: 4 n-6$ & $1 \cdot 8$ & 0.3 & $2 \cdot 0$ & 0.3 & $2 \cdot 1$ & 0.2 & 0.60 \\
\hline $20: 5 n-3$ & 0.5 & 0.1 & 0.5 & 0.1 & 0.4 & 0.1 & 0.54 \\
\hline $22: 6 n-3$ & 0.5 & 0.1 & 0.8 & 0.2 & 0.4 & 0.1 & 0.37 \\
\hline \multicolumn{8}{|l|}{ TAG } \\
\hline $16: 0$ & $29 \cdot 1$ & 1.7 & $28 \cdot 3$ & 1.9 & 30.9 & 1.0 & 0.12 \\
\hline $16: 1$ & $3 \cdot 0$ & 0.4 & $3 \cdot 0$ & 0.6 & $3 \cdot 4$ & 0.2 & $0 \cdot 24$ \\
\hline $16: 0: 16: 1$ & $9 \cdot 8$ & $1 \cdot 3$ & $9 \cdot 5$ & $1 \cdot 3$ & $9 \cdot 1$ & 0.9 & 0.57 \\
\hline $18: 0$ & $21 \cdot 1$ & $2 \cdot 0$ & $20 \cdot 1$ & 1.4 & 20.5 & 1.7 & 0.61 \\
\hline $18: 1$ & $30 \cdot 2$ & $1 \cdot 8$ & 32.9 & $2 \cdot 0$ & $33 \cdot 2$ & 1.4 & 0.04 \\
\hline 18:0:18:1 & 0.7 & 0.1 & 0.6 & 0.1 & 0.6 & 0.1 & 0.08 \\
\hline $18: 2 n-6$ & $14 \cdot 1$ & 1.4 & $12 \cdot 6$ & $1 \cdot 3$ & $12 \cdot 5$ & 0.7 & 0.10 \\
\hline $18: 3 n-3$ & 0.6 & $0 \cdot 2$ & 0.5 & 0.2 & 0.6 & 0.2 & 0.68 \\
\hline$c 9, t 11-C L A$ & 0.8 & 0.2 & 0.1 & 0.1 & 0.2 & 0.1 & $<0.001$ \\
\hline$t 10, c 12-C L A$ & 0.1 & 0.0 & 0.2 & 0.0 & 0.0 & 0.0 & $<0.001$ \\
\hline $20: 4 n-6$ & 0.9 & 0.2 & 0.9 & 0.2 & 0.9 & 0.2 & 0.95 \\
\hline $20: 5 n-3$ & 0.6 & 0.2 & 0.5 & 0.2 & 0.5 & 0.1 & $0 \cdot 10$ \\
\hline $22: 6 n-3$ & 0.4 & 0.1 & 0.5 & 0.1 & 0.5 & 0.1 & 0.75 \\
\hline
\end{tabular}

* Difference between groups (one-way ANOVA).

For details of subjects and procedures, see p. 728.

Table 5. Peak plasma concentrations ( $\mathrm{ng} / \mathrm{ml}$ plasma) and area under the curve ${ }^{\star}$ (AUC; $\mathrm{ng} / \mathrm{ml}$ plasma) for ${ }^{13} \mathrm{C}$-labelled linoleic acid (LA), linolenic acid (LNA), arachidonic acid (AA), EPA and DHA in subjects fed cis-9,trans-11 conjugated linoleic acid (c9,t11-CLA), trans-10,cis-12 conjugated linoleic acid ( $t 10, c 12-C L A)$ or olive oil placebo (control)

(Mean values with their standard deviations)

\begin{tabular}{|c|c|c|c|c|c|c|c|}
\hline & \multicolumn{6}{|c|}{ Study group } & \multirow[b]{3}{*}{$P+$} \\
\hline & \multicolumn{2}{|c|}{$c 9, t 11-C L A$} & \multicolumn{2}{|c|}{$t 10, c 12-C L A$} & \multicolumn{2}{|c|}{ Control } & \\
\hline & Mean & SD & Mean & SD & Mean & SD & \\
\hline \multicolumn{8}{|c|}{ Peak concentration (ng/ml) } \\
\hline$\left[{ }^{13} \mathrm{C}\right] \mathrm{LA}$ & 4.7 & $1 \cdot 3$ & $5 \cdot 6$ & 1.6 & $5 \cdot 0$ & $1 \cdot 2$ & 0.83 \\
\hline$\left[{ }^{13} \mathrm{C}\right]$ LNA & 1.3 & 0.3 & $1 \cdot 1$ & 0.7 & $1 \cdot 1$ & 0.4 & 0.84 \\
\hline$\left[{ }^{13} \mathrm{C}\right] \mathrm{AA}$ & 0.06 & 0.02 & 0.05 & 0.02 & 0.05 & 0.03 & 0.93 \\
\hline$\left[{ }^{13} \mathrm{C}\right] \mathrm{EPA}$ & 0.02 & 0.01 & 0.04 & 0.02 & 0.03 & 0.01 & 0.18 \\
\hline$\left[{ }^{13} \mathrm{C}\right] \mathrm{DHA}$ & 0.09 & 0.05 & 0.09 & 0.03 & 0.06 & 0.03 & 0.47 \\
\hline \multicolumn{8}{|l|}{ AUC (ng/ml) } \\
\hline$\left[{ }^{13} \mathrm{C}\right] \mathrm{LA}$ & 642 & 302 & 719 & 243 & 603 & 302 & 0.74 \\
\hline$\left[{ }^{13} \mathrm{C}\right]$ LNA & 45 & 19 & 50 & 19 & 68 & 42 & 0.42 \\
\hline$\left[{ }^{13} \mathrm{C}\right] \mathrm{AA}$ & 10 & 13 & $8 \cdot 2$ & $4 \cdot 3$ & 11 & 14 & 0.90 \\
\hline$\left[{ }^{13} \mathrm{C}\right] \mathrm{EPA}$ & 3.6 & 2.9 & $5 \cdot 8$ & 2.4 & 3.7 & 1.0 & 0.26 \\
\hline$\left[{ }^{13} \mathrm{C}\right] \mathrm{DHA}$ & 10 & 3.2 & 11 & 2.4 & $8 \cdot 4$ & $3 \cdot 2$ & 0.40 \\
\hline
\end{tabular}


${ }^{2} \mathrm{H}$-labelled metabolites were also present at low concentrations or at levels below accurate quantification, this was probably a methodological issue rather than an indication of inhibited desaturation and elongation.

Generally, supplementing human subjects with $0 \cdot 7-3.9 \mathrm{~g}$ CLA mixture/d has resulted in no or only minor changes in plasma fatty acids (Benito et al. 2001a; Mougios et al. 2001; Petridou et al. 2003). A significant decrease in LNA was detected when feeding a 50:50 mixture of $c 9, t 11$-CLA and $t 10, c 12$-CLA and a decrease in EPA when the same isomers were given in a 80:20 ratio (Noone et al. 2002). In a metabolic ward study with seventeen female subjects, CLA was incorporated into platelets at the expense of LA, but without changes in AA (Benito et al. 2001b).

In animals, on the other hand, inhibition of both $\Delta^{6}$-desaturase and elongase has been observed. Significant decreases (up to $50 \%$ ) in LA metabolites have been reported in mammary and adipose tissue of rats (Banni et al. 1999b), pigs (Kramer et al. 1998; Ramsay et al. 2001) and hens (Du et al. 2000). Decreases in LA metabolites were associated with the appearance of conjugated metabolites of CLA, CD18:3 and CD20:3 (Sebedio et al. 2001), which do not serve as substrates for eicosanoid synthesis but rather inhibit it (Nugteren \& Christ-Hazelhof, 1987). Liver and plasma were not affected (Sebedio et al. 2001), suggesting that the inhibitory effect of CLA may be seen in tissues with a high content of neutral lipids and CLA.

In tissues such as mammary and adipose tissue, the concentration of LA is low and competition between LA and CLA relatively favours CLA. When LA intake is also low, as in animal studies with fat-free or butter-fat diets, the situation is further aggravated. Due to the unavailability of these tissues from the present study it is not possible to determine whether this would have been the case in our subjects. However, considering that the average intake of LA exceeds that of CLA by over fiftyfold in most Western populations, the inhibitory effect of CLA is probably overcome by the excess of LA. The differences observed in human and animal studies in the effects of CLA on essential fatty acid metabolism may thus be partly explained by the high CLA:LA used in animal studies, not applicable to human studies. Also, species differences in the effects of CLA on gene expression, e.g. PPAR involved in the regulation of desaturases and other lipid-metabolizing enzymes, should be taken into account when interpreting results.

In line with previous studies (Banni et al. 2001; Sebedio et al. 2003), total CLA concentration was highest in TAG. $c 9, t 11$ CLA was incorporated mainly into TAG while accumulation of $t 10, c 12$-CLA was greatest in PC. The lower concentrations of $t 10, c 12$-CLA noted in the present as well as most other studies have been speculated to be due to increased metabolism because the $t 10, c 12$ isomer is more easily oxidized because its structure allows it to bypass rate-limiting steps of peroxisomal $\beta$-oxidation (Martin et al. 2000). However, Burdge et al. (2004) did not observe differences in incorporation of the $c 9, t 11$ and $t 10, c 12$ isomers after accounting for higher baseline concentrations of $c 9, t 11$-CLA.

The changes noticed in concentrations of 16:0 (increase in both CLA groups in CE) and 18:1 (decrease in TAG in the $c 9, t 11$ group) could be indications of decreased $\Delta^{9}$-desaturase activity. As a result, the concentration of saturated fatty acids increases at the expense of monounsaturates. However, the ratios 16:0:16:1 and 18:0:18:1, seen as indicators of
$\Delta^{9}$-desaturase activity, did not differ between groups in total fatty acids or in plasma lipid fractions. Also, Burdge et al. (2004) reported no changes in lipid fraction fatty acids in healthy men supplemented with one, two or four capsules containing approximately $600 \mathrm{mg} c 9, t 11$-CLA or $t 10, c 12$-CLA for 8 weeks. In cell culture and animal studies, $t 10, c 12$-CLA has been shown to alter $\Delta^{9}$-desaturase activity, i.e. increase 18:0 content at the expense of 18:1 (and thus increase 18:0:18:1) or alter the ratio of 16:1:16:0 (Li \& Watkins, 1998; Bretillon et al. 1999; Du et al. 2000).

The decreases in $n-6$ fatty acids have occasionally been balanced by an increase in the content of long-chain PUFA (22:5 and 22:6) when feeding $t 10, c 12-C L A$, an effect hypothesized to be due to stimulation of the peroxisomal fatty acid metabolism (Li \& Watkins, 1998; Du et al. 2000). Significant differences were not observed between groups in conversion of $\left[{ }^{13} \mathrm{C}\right] \mathrm{LNA}$ to $\left[{ }^{13} \mathrm{C}\right] \mathrm{EPA}$ or $\left[{ }^{13} \mathrm{C}\right] \mathrm{DHA}$, although increased concentrations of DHA in total plasma fatty acids were detected in both CLA groups compared with controls also in the present study. Since differences in DHA were not seen in plasma lipid fractions, it may be a chance result.

In conclusion, the present results indicate that the plasma appearance of long-chain PUFA derived from LA and LNA was not affected by an approximately $1.2 \mathrm{~g}$ daily intake of $c 9, t 11$-CLA or $t 10, c 12-C L A$ in subjects with intake of essential fatty acids within recommendations. We cannot exclude differences in tissues, but it is probable that, with present intake levels of LA, the excess of LA overcomes any effects of CLA. This also suggests that the availability of precursors for eicosanoid synthesis is not affected by CLA.

\section{Acknowledgements}

We gratefully acknowledge the cooperation of the subjects. This study was supported by the Cultural Foundation of Finland, the Juho Vainio Foundation, Finland, the Academy of Finland and National Institutes of Health (grant GM49209). None of the authors had any conflict of interest.

\section{References}

Aro A, Männistö S, Salminen I, Ovaskainen M-L, Kataja V \& Uusitupa M (2000) Inverse association between dietary and serum conjugated linoleic acid and risk of breast cancer in postmenopausal women. Nutr Cancer 38, 151-157.

Badinga L, Selberg KT, Dinges AC, Corner CW \& Miles RD (2003) Dietary conjugated linoleic acid alters hepatic lipid content and fatty acid composition in broiler chickens. Poult Sci 82, 111-116.

Banni S, Angioni E, Carta G, et al. (1999a) Influence of dietary conjugated linoleic acid on lipid metabolism in relation to its anticarcinogenic activity. In Advances in Conjugated Linoleic Acid Research, vol. 1, pp. 307-318 [MP Yurawecz, MM Mossoba, JKG Kramer, MW Pariza and GJ Nelson, editors]. Champaign, IL: AOCS Press.

Banni S, Angioni E, Casu V, Melis MP, Carta G, Corongiu FP, Thompson H \& Ip C (1999b) Decrease in linoleic acid metabolites as a potential mechanism in cancer risk reduction by conjugated linoleic acid. Carcinogenesis 20, 1019-1024.

Banni S, Carta G, Angioni E, Murru E, Scanu P, Melis MP, Bauman DE, Fischer SM \& Ip C (2001) Distribution of conjugated linoleic acid and metabolites in different lipid fractions in the rat liver. $J$ Lipid Res 42, 1056-1061.

Belury MA (2002) Inhibition of carcinogenesis by conjugated linoleic acid: potential mechanisms of action. J Nutr 132, 2995-2998. 
Belury MA \& Kempa-Steczko A (1997) Conjugated linoleic acid modulates hepatic lipid composition in mice. Lipids 32, 199-204.

Benito P, Nelson GJ, Kelley DS, Bartolini G, Schmidt PC \& Simon V (2001a) The effect of conjugated linoleic acid on platelet function, platelet fatty acid composition, and blood coagulation in humans. Lipids 36, 221-227.

Benito P, Nelson GJ, Kelley DS, Bartolini G, Schmidt PC \& Simon V (2001b) The effect of conjugated linoleic acid on plasma lipoproteins and tissue fatty acid composition in humans. Lipids 36, 229-236.

Bligh E \& Dyer W (1959) A rapid method of total lipid extraction and purification. Can J Biochem Physiol 37, 911-917.

Bretillon L, Chardigny JM, Gregoire S, Bordeaux O \& Sebedio JL (1999) Effects of conjugated linoleic acid isomers on the hepatic microsomal desaturation activities in vitro. Lipids 34, 965-969.

Burdge GC, Lupoli B, Russell JJ, et al. (2004) Incorporation of cis9,trans-11 or trans-10,cis-12 conjugated linoleic acid into plasma and cellular lipids in healthy men. J Lipid Res 45, 736-741.

Chuang L-T, Thurmond JM, Liu JW, Kirchner SJ, Mukerji P, Bray TM \& Huang Y-S (2001a) Effect of conjugated linoleic acid (CLA) on fungal delta-6-desaturase activity in a transformed yeast system. Lipids 36, 139-143.

Chuang L-T, Leonard AE, Liu J-W, Mukerji P, Bray TM \& Huang Y-S (2001b) Inhibitory effect of conjugated linoleic acid on linoleic acid elongation in transformed yeast with human elongase. Lipids 36, 1099-1103.

Du M, Ahn DU \& Sell JL (2000) Effects of dietary conjugated linoleic acid and linoleic:linolenic acid ratio on polyunsaturated fatty acid status in laying hens. Poult Sci 79, 1749-1756.

Emken EA, Adlof RO, Duval S, Nelson G \& Benito P (2002) Effect of dietary conjugated linoleic acid (CLA) on metabolism of isotope-labeled oleic, linoleic, and CLA isomers in women. Lipids 37, $741-750$.

Fremann D, Linseisen J \& Wolfram G (2002) Dietary conjugated linoleic acid (CLA) intake assessment and possible biomarkers of CLA intake in young women. Public Health Nutr 5, 73-80.

Goodman KJ \& Brenna JT (1992) High sensitivity tracer detection using high-precision gas chromatography-combustion isotope ratio mass spectrometry and highly enriched $\left(\mathrm{U}_{-}{ }^{13} \mathrm{C}\right)$-labeled precursors. Anal Chem 64, 1088-1095.

Kramer JK, Sehat N, Dugan ME, Mossoba MM, Yurawecz MP, Roach JA, Eulitz K, Aalhus JL, Schaefer AL \& Ku Y (1998) Distributions of conjugated linoleic acid (CLA) isomers in tissue lipid classes of pigs fed a commercial CLA mixture determined by gas chromatography and silver ion-high-performance liquid chromatography. Lipids 33, 549-558.

Li Y \& Watkins BA (1998) Conjugated linoleic acids alter bone fatty acid composition and reduce ex vivo prostaglandin $\mathrm{E}_{2}$ biosynthesis in rats fed $n-6$ or $n-3$ fatty acids. Lipids 33, 417-425.

Loor JJ, Lin X \& Herbein JH (2003) Effects of dietary cis 9, trans 1118:2, trans 10 , cis $12-18: 2$, or vaccenic acid (trans 11-18:1) during lactation on body composition, tissue fatty acids profiles, and litter growth in mice. Br J Nutr 90, 1039-1048.
Martin JC, Gregoire S, Siess MH, Genty M, Chardigny JM, Berdeaux O, Juaneda P \& Sebedio JL (2000) Effects of conjugated linoleic acid isomers on lipid metabolizing enzymes in male rats. Lipids 35, 91-98.

Matthews JNS, Altman DG, Campbell MJ \& Royston P (1990) Analysis of serial measurements in medical research. BMJ $\mathbf{3 0 0}$, $230-235$.

Mougios V, Matsakas A, Petridou A, Ring S, Sagredos A, Melissopoulou A, Tsigilis N \& Nikolaidis M (2001) Effect of supplementation with conjugated linoleic acid on human serum lipids and body fat. J Nutr Biochem 12, 585-594.

Noone EJ, Roche HM, Nugent AP \& Gibney MJ (2002) The effect of supplementation using isomeric blends of conjugated linoleic acid on lipid metabolism in healthy human subjects. Br J Nutr 88, $243-251$.

Nugteren DH \& Christ-Hazelhof E (1987) Naturally-occurring conjugated octadecatrienoic acids are strong inhibitors of prostaglandin biosynthesis. Prostaglandins 33, 403-417.

Ostrowska E, Cross RF, Muralitharan M, Bauman DE \& Dunshea FR (2003) Dietary conjugated linoleic acid differentially alters fatty acid composition and increases conjugated linoleic acid content in porcine adipose tissue. Br J Nutr 90, 915-928.

Pariza MW, Park Y \& Cook ME (2001) The biologically active isomers of conjugated linoleic acid. Prog Lipid Res 40 , 283-298.

Petridou A, Mougios V \& Sagredos A (2003) Supplementation with CLA: isomer incorporation into serum lipids and effect on body fat of women. Lipids 38, 805-811.

Ramsay TG, Evock-Clover CM, Sttele NC \& Azain MJ (2001) Dietary conjugated linoleic acid alters fatty acid composition in pig skeletal muscle and fat. J Anim Sci 79, 2152-2161.

Ritzenthaler KL, McGuire MK, Falen R, Shultz TD, Dasgupta N \& McGuire MA (2001) Estimation of conjugated linoleic acid intake by written dietary assessment methodologies under estimates actual intake evaluated by food duplicate methodology. J Nutr 131, 1548-1554.

Scheaff RC, Su H-M, Keswick LA \& Brenna JT (1995) Conversion of $\alpha$-linolenate to docosahexaenoate is not depressed by high dietary levels of linoleate in young rats: tracer evidence using high precision mass spectrometry. J Lipid Res 36, 998-1008.

Sebedio JL, Angioni E, Chardigny JM, Gregoire S, Juaneda P \& Berdeaux O (2001) The effect of conjugated linoleic acid isomers on fatty acid profiles of liver and adipose tissues and their conversion to isomers of $16: 2$ and 18:3 conjugated fatty acids in rats. Lipids 36, 575-582.

Sebedio JL, Chardigny JM \& Berdeaux O (2003) Metabolism of conjugated linoleic acids. In Advances in Conjugated Linoleic Acid Research, pp. vol. 2, 259-266 [JL Sebedio, WW Christie and R Adlof, editors]. Champaign, IL: AOCS Press.

Turpeinen AM, Mutanen M, Aro A, Salminen I, Basu S, Palmquist DL \& Griinari JM (2002) Bioconversion of vaccenic acid to conjugated linoleic acid in humans. Am J Clin Nutr 76, 504-510. 